\title{
AN ALLELE-SPECIFIC SUPPRESSOR OF WHITE-CORAL IN DROSOPHILA MELANOGASTER
}

\author{
JAMES L. FARMER \\ Department of Zoology, Brigham Young University, Provo, Utah 84602, U.S.A.
}

Received 2.ii.77

\section{Summary}

\begin{abstract}
A new allele of white-coral $\left(w^{c o 2}\right)$ was isolated from Canton $\mathrm{S}$ after mutagenesis. Many common laboratory stocks were found to carry a suppressor gene $\left(S u\left(w^{c o 2}\right)\right)$ which alters the phenotype of $w^{c o 2}$ flies toward wild-type. The $S u\left(w^{c o 2}\right)$ is allele-specific (it does not suppress $w^{c o}$ ), dominant, homozygous viable, located near $S u\left(b w^{v 1}\right)$ on the right arm of chromosome 2, and shows a simple gene-dosage effect. The degree of suppression is sensitive to the genetic background. There appears to be selection for $S u\left(w^{c o s}\right)$ in a genotype where it does not affect eye pigmentation.
\end{abstract}

\section{INTRODUGTION}

A NEw allele at the white locus is not a novelty. Lindsley and Grell (1968) listed 142 alleles at the white locus, and several more have been reported since, although only two alleles identified as white-coral have been reported. Suppressors of alleles at the white locus are more rare. The only specific suppressors of white pseudoalleles listed by Lindsley and Grell (1968) are those which suppress some of the white-apricot alleles. These suppressors map near but not in the white locus. Lee (1972) reported a recessive suppressor of white-honey which is on chromosome 3 , but it has not been further characterised.

Of the 11 dominant suppressors listed by Lindsley and Grell (1968), four are homozygous lethal, four are homozygous viable, one has greatly reduced viability when homozygous, and viability data are not available for the other two.

This paper reports the isolation of a new allele at the white locus with white-coral eye colour and the discovery and characterisation of a suppressor of the new allele.

\section{Materials AND METHODS}

Stocks and abbreviations. Original stocks were obtained from the Department of Zoology, University of California, Berkeley; Division of Biology, California Institute of Technology, Pasadena; Mid-America Drosophila Stock Centre, Bowling Green State University, Ohio; and Department of Genetics, University of California, Davis. The abbreviations used are those in Lindsley and Grell (1968). The new mutant $w^{c 02}$ was originally designated $w^{c o J}$ (Farmer, 1974).

Growth of stocks. Stocks were maintained at $17^{\circ}$ and $25^{\circ} \mathrm{C}$. Experimental crosses were maintained at the higher temperature. The media used were standard cornmeal-molasses-agar with either yeast or Wheast (a commercial fermentation of whey).

$39 / 2-\mathrm{H}$ 
Extraction of pigments. In early experiments the drosopterins were extracted by grinding 10 freshly decapitated male heads in $1 \mathrm{ml}$ of 1 per cent ammonium hydroxide with a glass homogeniser, as described by Glassman and Mitchell (1959). Later it was found to be more satisfactory to use an acidic-ethanol extraction procedure, as described by Schwinck and Mancini (1973). For chromatography, the heads from 10 freshly decapitated, 5 to 7 -day-old males or females were incubated in $0.1 \mathrm{ml}$ of 30 per cent ethanol (brought to $\mathrm{pH} 2$ with $\mathrm{HCl}$ ) in the dark at $37^{\circ} \mathrm{G}$ for 48 hours. For quantification of drosopterins, the same procedure was used, except that one head was placed in $1 \mathrm{ml}$ of solvent. Extraction of drosopterins under the last conditions mentioned above is essentially complete (the optical density at $480 \mathrm{~nm}$ reaches a plateau) after 33 to 37 hours.

Quantification and chromatography of pigments. Drosopterins were quantified by measuring the optical density of head crude extracts at $480 \mathrm{~nm}$. Other pterin pigments were examined by chromatography. Ascending chromatography of ammonium hydroxide extracts was done on paper (Whatman No. 1) or Eastman cellulose Chromagram sheets with the following solvents: 2 : 1 isopropanol and 1 per cent ammonium hydroxide; $4: 1: 5 n$-butanol, acetic acid, and water; and $2: 1 n$-propanol and 1 per cent acetic acid. Acidic-alcohol extracts were developed by ascending chromatography on Eastman cellulose Chromagram sheets using a $2: 1$ mixture of $n$-propanol and 1 per cent acetic acid as solvent for one-dimensional chromatography or the method of Schwinck and Mancini (1973) for two-dimensional chromatography.

Population cage. To test the effect of competition on the frequency of $S u\left(w^{c o 2}\right)$, a population cage was made from a plastic refrigerator dish approximately 7.7 litres in capacity with 12 food cups attached. Three food cups were replaced with cups containing fresh medium approximately weekly. Males eclosing from old food cups were used in test crosses to determine gene frequency for the first five experimental points. Males were removed directly from the cage to determine the frequency at 132 days, when the competition experiment was terminated.

The $S u^{+}\left(w^{c o 2}\right)$ allele used in this experiment was originally derived from a Basc stock and was placed in the $w$ stock by a cross between $w ; S u\left(w^{c o 2}\right)$ males and $w^{c o 2} ; S u^{+}\left(w^{c o 2}\right)$ females, resulting in the $w ; S u^{+}\left(w^{c o 2}\right)$ stock in the F4. The $S u\left(w^{c o 2}\right)$ allele used in this experiment was originally derived from Canton $\mathrm{S}$ and was placed in the $w$ stock by a cross between $w^{c o 2} ; S u\left(w^{c o 2}\right)$ males and $w ; S u^{+}\left(w^{c 02}\right)$ females, resulting in the $w ; S u\left(w^{c o 2}\right) / S u^{+}\left(w^{c o 2}\right) \mathrm{F} 1$ males used in this experiment. Since the chromosomes carrying the two alleles are not otherwise isogenic, there is a possibility that an increase in the frequency of one of the alleles might be due to selection for other genes which are closely linked to $S u\left(w^{c o 2}\right)$.

\section{Results}

Discovery and characterisation of white-coral 2: Canton $\mathrm{S}$ malcs were treated with ethylmethanesulphonate by the procedure of Lewis and Bacher (1968) and mated to Basc females. Individual $\mathrm{Fl}$ pairs were mated in vials. The F2 progeny of one F1 pair included flies with dark brown eyes, similar in colour to mutants such as $w^{c o}$ and bw in which drosopterin pigments are greatly reduced. 
The mutant, designated $w^{c o 2}$, was identified as white-coral by the following criteria: (1) $w^{c o}$ and $w^{c o 2}$ flies have the same eye colour; (2) $w^{c o 2}$ maps in the white locus; only 1 wild-type recombinant was observed among 12,401 progeny of the cross $w^{c o 2} / w$ female $\times w$ male (the $w$ stock used in this cross was homozygous for the wild-type allele of the suppressor described below); (3) $w^{c o}$ and $w^{c o 2}$ flies contain the same eye pigments in the same proportions (see RESUlTs below); (4) females heterozygous for $w^{c o 2}$ and $w^{i}$ or $w^{a}$ have the same eye colour as homozygous $w^{c o 2}$ females; (5) $w^{c o}$ and $w^{c o 2}$ males have pigmented testis sheaths, unlike $w^{B w x}$ (Lindsley and Grell, 1968).

Discovery and characterisation of suppressor of $\mathrm{w}^{c o 2}$. In order to verify the suspected location of $w^{c o 2}$ on the $\mathrm{X}$ chromosome, $w^{c o 2}$ males were crossed with Canton $\mathrm{S}$ females. The F1 all had wild-type eye colour. The F2 produced 172 males of which only 23 had coral eye colour, when 86 were expected. Crosses of $w^{c 02}$ females with males of several different mutant stocks showed that all Fl males from some crosses were coral, while all F1 males from the other crosses were not coral. Eye colour for a given Fl of the latter category was fairly uniform, but the different Fl progenies varied from wild-type to a dark, but not coral, reddish-brown.

The simplest interpretation of the above data is that some stocks carry an autosomal, dominant suppressor of $w^{c o 2}$ which is allele specific, since $w^{c o}$ stocks also carry the suppressor. In retrospect, the $\mathrm{F} 2$ results from the above cross between Ganton S and $w^{c o 2}$ agree well with this hypothesis. If one-half of the F2 males were expected to be $w^{c o 2}$ and three-quarters of those were expected to be suppressed, then the expected number of wild-type and coral males would have been $150 \cdot 5$ and $21 \cdot 5$, respectively (the observed numbers were 149 and 23 ).

To test the above hypothesis, F2 males from a cross between Canton S females and $w^{c o 2}$ males were test-crossed to $w^{c o 2}$ females. The results, shown in table 1 , are consistent with the hypothesis.

TABLE 1

Testcross* of individual " wild-type" males from F2 progeny of Canton $S$ \& $\times \mathrm{w}^{\mathrm{co} 2} \sigma^{*}$

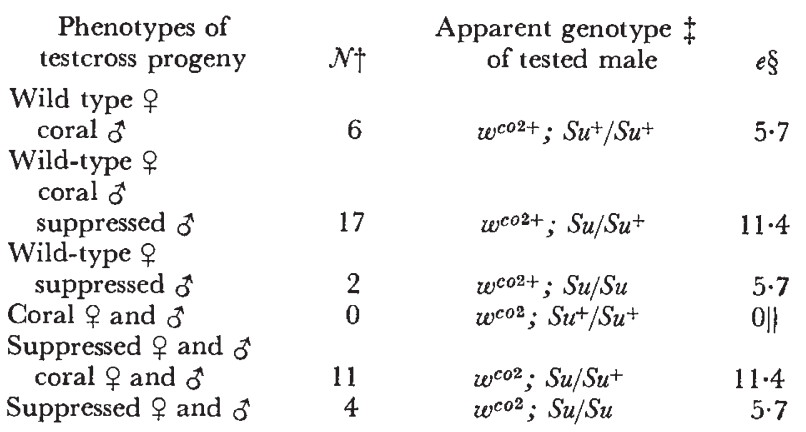

* Testcrossed to $w^{c o 2}$ females, one pair per vial.

$\dagger \mathcal{N}$ is the number of tested males which produced progeny of the indicated types.

$+S u$ is $S u\left(w^{c o 2}\right)$.

$\S e$ is the expected value of $\mathcal{N}$, assuming a $1: 1$ ratio of $w^{c 02+}$ to $w^{c 02}$ and a $1: 2: 1$ ratio of $S u^{+} / S u^{+}$to $S u / S u^{+}$to $S u / S u$, each gene assorting independently. Chi-square $=5 \cdot 69$; degrees of freedom $=4 ; \mathrm{P}=0.22$.

If Since only males with non-coral eyes were tested, no progeny of this type were expected. 
The progeny of the above testcross was used to prepare stocks which were homozygous for both $w^{c o 2}$ and the suppressor. Some of these stocks produced only flies with bright red eyes, clearly more red than Canton S. One of these was chosen and used for subsequent experiments. It is called $S u\left(w^{c o 2}\right)$. Other stocks produced both bright-red-eyed and dull-red-eyed flies, or only dull-red-eyed flies. All flies, however, were clearly not coral. There are apparently other genes which modify the effect of the suppressor gene. The effect of the hypothetical modifiers can be more clearly seen in the male progeny of crosses where the female parent was $w^{c o 2} v$, thus eliminating interference from the brown pigments. Depending on the cross, such males may have eye colours ranging from gold (the unsuppressed colour) through pale orange, pink, and red to bright vermilion. The modifiers have not been analysed. In most of the subsequent experiments $w^{c o 2} v$ flies were used in order to avoid the difficulty of scoring suppressed coral eye colour in the presence of the brown pigments, since in some crosses the suppressed eye colour differs only slightly from coral.

Effect of $\mathrm{Su}\left(w^{c o 2}\right)$ on drosopterin pigments. Initially, the homozygous suppressed $w^{c 02}$ contained more drosopterin per fly than Canton S. After about 8 months, however, the stock had " faded " and contained considerably less drosopterin per fly than Canton S. This change was clearly apparent in intact flies examined under the microscope and was verified when pigments were quantified (table 2). The ratio of drosopterin content of $w^{c o 2} ; S u\left(w^{c o 2}\right)$ males to Canton $\mathrm{S}$ males was 1.35 initially, but dropped to 0.668 months later.

TABle 2

Quantification of drosopterin content

\begin{tabular}{|c|c|c|c|c|}
\hline \multirow[b]{2}{*}{ Genotype* } & \multicolumn{4}{|c|}{ Mean absorbance at $480 \mathrm{~nm} \pm$ standard deviation $\dagger$} \\
\hline & Alkali extract & $\mathcal{N}_{+}^{+}$ & Acidic-ethanol extract & $\mathcal{N}_{+}^{+}$ \\
\hline Canton S đ & $0.528 \pm 0.097$ & 5 & $0.074 \pm 0.005$ & 10 \\
\hline Canton $\mathrm{S}$ 우 & & & $0.083 \pm 0.006$ & 10 \\
\hline vo & $0.452 \pm 0.010$ & 2 & & \\
\hline bw vg o & 0.094 & 1 & & \\
\hline$w d$ & $0.034 \pm 0.001$ & 2 & & \\
\hline$w^{c 02} ; S u^{+} / S u^{+} \sigma^{+}$ & $0.097 \pm 0.023$ & 4 & $0.008 \pm 0.001$ & 3 \\
\hline$w^{c o 2} / w^{c o 2} ; S u^{+} / S u^{+}$우 & & & $0.007 \pm 0.002$ & 6 \\
\hline$w^{c o 2} ; S u / S u^{+} \sigma^{*}$ & $0.436 \pm 0.035$ & 3 & $0.034 \pm 0.004$ & 8 \\
\hline$w^{c 0^{2} / w^{c o^{2}}} ; S u / S u^{+}$ㅇ & & & $0.033 \pm 0.004$ & 10 \\
\hline$w^{c 02} ; S u / S u$ ठ & $0.715 \pm 0.048$ & 3 & $0.049 \pm 0.006$ & 9 \\
\hline$w^{c o 2} / w^{c o 2} ; S u / S u$ 우 & & & $0.053 \pm 0.007$ & 10 \\
\hline$w^{c o 2} / w ; S u^{+} / S u^{+}+$ & & & $0.006 \pm 0.001$ & 10 \\
\hline$w^{c o 2} / w ; S u / S u^{+}$ㅇ & & & $0.018 \pm 0.004$ & 10 \\
\hline$w^{c 02} v ; S u^{+} / S u^{+} \delta$ & 0.095 & 1 & $0.008 \pm 0.002$ & 10 \\
\hline$w^{c o 2} v ; S u / S u^{+} \sigma^{+}$ & & & $0.037 \pm 0.004$ & 10 \\
\hline$z^{c o} \mathrm{O}^{\mathrm{C}}$ & $0.117 \pm 0.026$ & 3 & $0.008 \pm 0.003$ & 10 \\
\hline$z e^{c o} ; S u / ?$ ơ $\delta$ & $0.118 \pm 0.001$ & 2 & $0.006 \pm 0.002$ & 10 \\
\hline
\end{tabular}

* $S u$ is $S u\left(w^{c 0^{2}}\right)$.

$\uparrow$ Alkali extracts contained 10 heads per tube; acidic-ethanol extracts contained one head per tube. Each tube contained $1 \mathrm{ml}$ solvent. Alkali extracts were prepared on 15 th August 1973; acidic-ethanol extracts were prepared on 2nd to 4th April 1974.

$\ddagger \mathcal{N}$ is the number of measurements.

$\S w^{c o}$ stocks carry $S u\left(w^{c 0^{2}}\right)$. $w^{c o}$ was crossed with $w^{c o^{2}} ; S u\left(w^{c 0^{2}}\right)$ to produce these males. 
The suppressor does not increase the drosopterin content of $w^{c o}$ flies (table 2), thus the suppressor is allele-specific.

The gene $w^{c o 2}$ is dosage compensated, since suppressed males make as much of the drosopterins as suppressed females, while heterozygous $w^{c 02} / w$ females make only 54 per cent as much of the drosopterins as homozgyous $w^{c o 2}$ females, when each is heterozygous for the suppressor (table 2). The gene $S u\left(w^{c o 2}\right)$ shows a simple gene-dosage effect; heterozygous suppressed $w^{c o 2}$ flies make 62 per cent to 69 per cent as much of the drosopterins as homozygous suppressed flies (table 2). The difference in drosopterin content between $w^{c o 2}$ flies which were homozygous or heterozygous for the suppressor was also clearly visible on chromatograms, both by visual inspection and by densitometer tracing.

Pterin pigments other than the drosopterins do not seem to be affected by $w^{c o 2}, w^{c o}$, or $S u\left(w^{c o 2}\right)$ as judged by visual inspection of chromatograms under ultraviolet light. Two-dimensional chromatography of head extracts from $w^{c o 2} ; S u\left(w^{c o 2}\right)$ and Canton $\mathrm{S}$ revealed no differences in positions or relative intensities of the various drosopterins between these two stocks.

$\mathcal{N}_{0}$ interaction of $\mathrm{w}^{c 02}$ or $\mathrm{Su}\left(\mathrm{w}^{c 02}\right)$ with zeste. Stocks of $z^{58 g}$ were made heterozygous for $S u\left(w^{c o 2}\right)$ and homozygous for $S u^{+}\left(w^{c o 2}\right)$. In both stocks the zeste eye colour was unchanged. Since $z^{58 g}$ normally carries $S u\left(w^{c o 2}\right)$ in a homozygous condition, the latter allele clearly does not affect the zeste eye colour. Females heterozygous for $z^{58 g}$ and $w^{c o 2}$ had a wild-type eye colour.

Distribution and mapping of $\mathrm{Su}\left(\mathrm{w}^{\mathrm{co} 2}\right)$. Fifteen of 18 stocks which have been tested carry $S u\left(w^{c o 2}\right)$. There is no apparent pattern which would allow prediction of the presence or absence of $S u\left(w^{c o 2}\right)$ in any given stock. In all stocks tested which carry $S u\left(w^{c o 2}\right)$ it is autosomal, and in at least four stocks it is on chromosome 2. It is assumed that there is only one locus for $S u\left(w^{c o 2}\right)$. Recombination frequency data for $S u\left(w^{c o 2}\right)$ are given in table 3. Neglecting the cross-over data with Bristle since that allele may reduce crossing-over (Lindsley and Grell, 1968), the most likely position of $\mathrm{Su}\left(w^{c 02}\right)$ is approximately 103 .

Competition between $\mathrm{Su}\left(\mathrm{w}^{\mathrm{co} 2}\right)$ and $\mathrm{Su}^{+}\left(\mathrm{w}^{\mathrm{co}^{2}}\right)$ in a population cage. Four males of genotype $w ; S u\left(w^{c o 2}\right) / S u^{+}\left(w^{c o 2}\right)$ were placed in a population cage with 11 females of genotype $w ; S u^{+}\left(w^{c o 2}\right)$. At various times males were recovered and mated individually with $w^{c o 2} v$ females in order to determine the genotype of each male. The results are shown in fig. 1. A least-squares fit generates a straight line (shown in fig. 1) which has slope 0.0020 day $^{-1}$ and intercept

TABLE 3

Recombination frequency data for $\mathrm{Su}\left(\mathrm{w}^{\mathrm{co} 2}\right)$

\begin{tabular}{|c|c|c|}
\hline Cross* & $\begin{array}{l}\text { Crossover } \\
\text { progeny } \\
\text { Scored } \\
\text { progeny }\end{array}$ & $\begin{array}{l}\text { Recombination } \\
\text { frequency }\end{array}$ \\
\hline 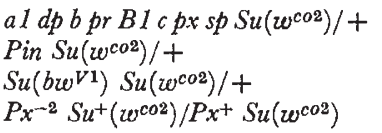 & $\begin{array}{l}223 / 593 \\
13 / 408 \\
2 / 135 \\
22 / 432\end{array}$ & $\begin{array}{c}38 \text { to right of } B 1 \\
3 \cdot 2 \\
1 \cdot 5 \\
5 \cdot 1\end{array}$ \\
\hline
\end{tabular}

* The females shown above were all homozygous $w^{c 02}$ and were mated to $w^{c o 2}$ males. 


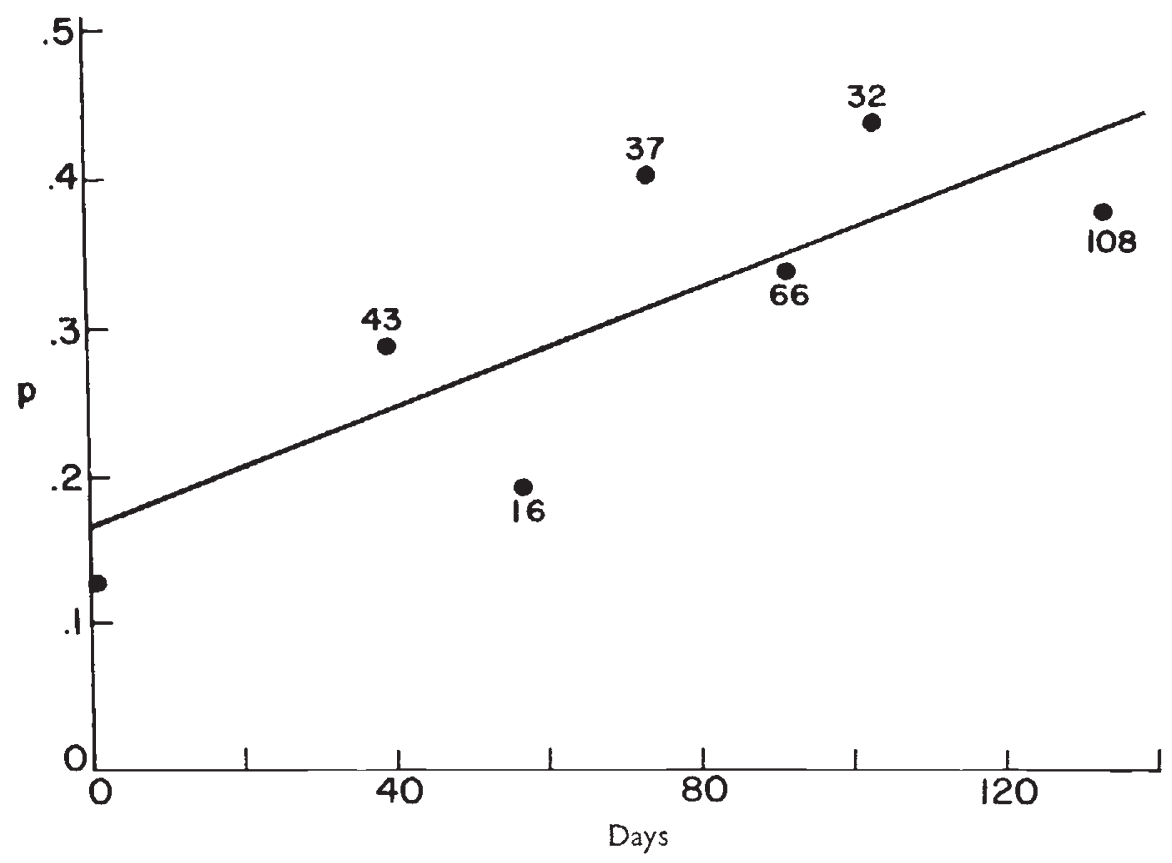

FIG. 1. Change in frequency of $S u\left(w^{c 0^{2}}\right)$ in a population cage. The frequency of $S u\left(w^{c 0^{2}}\right)$ is represented by $p$. The number by each point is the number of males tested for that point.

$0 \cdot 17$. However, it may be misleading to include the first point in the leastsquares fit, since the calculated frequency of the parent population might be expected to change rapidly, considering the genotypes and numbers of that initial population. If the first point is omitted, the least-squares fit generates a straight line with slope 0.0014 day $^{-1}$ and intercept 0.23 .

\section{Discussion}

The $S u\left(w^{c o 2}\right)$ is isoallelic to $S u^{+}\left(w^{c o 2}\right)$ since the two alleles are indistinguishable except in the presence of $w^{c 02}$. It is similar to $S u(e r)$ in that it is found in many common laboratory stocks (Glass, 1957). However, even though $S u\left(w^{c o 2}\right)$ is isoallelic to $S u^{+}\left(w^{c o 2}\right)$ as far as morphological phenotype is concerned, it may enhance viability or fertility, since there appears to be positive selection for it in a population where it does not affect eye pigmentation.

With the exception of $s u\left(w^{h}\right)$ which is unmapped but on chromosome 3 (Lee, 1972), specific suppressors of white-locus mutants are on the X chromosome, near the white locus. Although $S u\left(w^{c 02}\right)$ is on chromosome 2, it is located near several genes which affect eye colour (Punch (97), pinkish (100), brown (104.5), Suppressor of brown-Variegated-1 (105.2), purpleoid (106.4), orange $(107 \cdot 0)$. The position assigned to $S u\left(w^{c 02}\right)$ is subject to revision (103), but it is clearly near $S u\left(b w^{V 1}\right)$ and therefore bw, each of which also specifically affects drosopterin pigments.

Although the nature and mode of action of the $S u\left(w^{c o 2}\right)$ gene product 
are unknown, the fact that it is allele-specific and isoallelic eliminates some possibilities, such as an alternative pathway of drosopterin synthesis.

The "fading" of the eye colour in the $w^{c o 2} ; S u\left(w^{c o 2}\right)$ stock implies some selection for alleles of other genes which modify the effect of the suppressor. The cause of this phenomenon is unclear, since the suppressor is normally homozygous in many stocks and is apparently selected for in competition with the wild-type allele. Since flies with reduced drosopterin content presumably cannot see as well as wild-type flies, there must be some compensating reason why a reduced effect of the suppressor (decrease in drosopterin content) is selected for.

Smith and Lucchesi (1969) reported that $w^{+}$and $w^{a}$ are dosage compensated, while $w^{e}$ is not. The observation that $w^{c o 2}$ is dosage compensated when suppressed was expected since $w^{c o}$ is reported to be at the same pseudoallelic locus as $w^{a}$. The gene-dosage effect noted for $S u\left(w^{c o 2}\right)$ is not unusual. However, it suggests that the gene product of the suppressor may not be involved in regulation or some other function where a very small amount of gene product might be expected to produce a normal phenotype.

Acknowledgments. - I would like to thank Duane Jeffery and Mel Green for many helpful discussions. This work was supported in part by funds supplied by the Research Division of Brigham Young University. The zeste crosses were done during a leave at the University of California at Davis.

\section{REFERENGES}

FARmer, J. L. 1974. Report of J. L. Farmer. Drosoph. Inf. Serv., 51, 20.

GLASS, B. 1957. In pursuit of a gene. Science, 126, 683-689.

Glassman, E., AND mitchell, H. K. 1959. Mutants of Drosophila melanogaster deficient in xanthine dehydrogenase. Genetics, 44, 153-162.

LEE, G. L. 1972. Report of G. L. Lee. Drosoph. Inf. Serv., 48, 18-19.

LEWIS, E. B., AND BACHER, F. 1968. Method of feeding ethylmethane-sulfonate (EMS) to Drosophila males. Drosoph. Inf. Serv., 43, 193.

LINDSLEY, D. L., AND GRELl, E. H. 1968. Genetic variations of Drosophila melanogaster. Carnegie Inst. Washington Publ. 627.

SCHWINGK, I., AND MANGINI, M. 1973. The drosopterin patterns in various eye color mutants of the fruitfly Drosophila melanogaster. Arch. Genetik, 46, 41-52.

SMTTH, P. D., AND Lucahesi, J. G. 1969. The role of sexuality in dosage compensation in Drosophila. Genetics, 61, 607-618. 